\title{
Working with boundaries in systems psychodynamic consulting
}

\author{
Authors: \\ Henk Struwig ${ }^{1}$ \\ Frans Cilliers ${ }^{1}$ \\ Affiliations: \\ ${ }^{1}$ Department of Industrial \\ and Organisational \\ Psychology, UNISA, \\ South Africa \\ Correspondence to: \\ Frans Cilliers \\ Email: \\ cillifvn@unisa.ac.za \\ Postal address: \\ PO Box 392, UNISA 0003, \\ South Africa \\ Dates: \\ Received: 31 May 2011 \\ Accepted: 08 Dec. 2011 \\ Published: 22 Mar. 2012 \\ How to cite this article: \\ Struwig, H., \& Cilliers, \\ F. (2012). Working with \\ boundaries in systems \\ psychodynamic consulting. \\ SA Journal of Industrial \\ Psychology/SA Tydskrif vir \\ Bedryfsielkunde, 38(2), Art. \\ \#987, 10 pages. http:// \\ dx.doi.org/10.4102/sajip. \\ v38i2.987
}

Orientation: The researcher described the systems psychodynamics of boundary management in organisations. The data showed how effective boundary management leads to good holding environments that, in turn, lead to containing difficult emotions.

Research purpose: The purpose of the research was to produce a set of theoretical assumptions about organisational boundaries and boundary management in organisations and, from these, to develop a set of hypotheses as a thinking framework for practising consulting psychologists when they work with boundaries from a systems psychodynamic stance.

Motivation for the study: The researcher used the belief that organisational boundaries reflect the essence of organisations. Consulting to boundary managers could facilitate a deep understanding of organisational dynamics.

Research design, approach and method: The researcher followed a case study design. He used systems psychodynamic discourse analysis. It led to six working hypotheses.

Main findings: The primary task of boundary management is to hold the polarities of integration and differentiation and not allow the system to become fragmented or overly integrated. Boundary management is a primary task and an ongoing activity of entire organisations.

Practical/managerial implications: Organisations should work actively at effective boundary management and at balancing integration and differentiation. Leaders should become aware of how effective boundary management leads to good holding environments that, in turn, lead to containing difficult emotions in organisations.

Contribution/value-add: The researcher provided a boundary-consulting framework in order to assist consultants to balance the conceptual with the practical when they consult.

\section{Introduction}

\section{Background to the study}

Consultants have given far too little attention to organisational boundaries in consulting psychology. In this study, the researcher studied dynamic boundary management as a primary activity in organisations. It yielded very interesting findings. Every part of organisational systems operates within and across their own boundaries (Cilliers \& Koortzen, 2005; Koortzen \& Cilliers, 2002). By focusing on boundaries, consultants will always work with organisations as systems of interrelated parts and relationships between people (Diamond \& Allcorn, 2009).

Lawrence (1999) explained that boundaries are necessary in order for human beings to relate to each other and to their organisations. If there are no boundaries, relatedness and relationships are impossible because we become one, lost in each other, lost in organisations and lost in societies. By focusing on relationships and boundaries, consultants work directly with the essence of organisations.

Over the last few decades, the consulting literature has criticised positivism for its confined and narrow thinking, its focus on simplified cause and effect relationships (Lewis \& Kelemen, 2002) as well as its simplistic and deterministic constructs (Goldkuhl, 2002). There is a growing awareness that the social, economic and cultural realities of life in organisations are complex and multi-dimensional (Kegan, 1994). This requires an interpretive stance towards understanding and making meaning.

The movement of social science from simple exclusive paradigms towards complex inclusive paradigms that take into account the holistic, systemic, dynamic and chaotic aspects of behaviour in organisations mirror this awareness (Fuqua \& Newman, 2002). Organisational consulting psychology will remain relevant as long as it can draw on thinking frameworks and consulting 
processes that are able to deal with complexity and the depth of the human experience (Haslebo \& Nielsen, 2000). The systems psychodynamic perspective provides such a paradigm. It deals with complexity and relationships on a systemic, dynamic and psychological level (Colman \& Geller, 1985; Czander, 1993; Gould, Stapley \& Stein, 2001).

A key concept in systems psychodynamics is that of individual, group and organisational boundaries (Lawrence, 1999; Diamond \& Allcorn, 2009). They seem to be more relevant than ever in our time. Vansina and Vansina-Cobbaert (2008, p. 390) wrote that 'Collaboration and partnership are popular discourse in the $21^{\text {st }}$ century ... working across boundaries has become increasingly important in a world where organisations are intertwined and interdependent'. They made the point that the task of working across the boundaries of business units, departments, disciplines and hierarchical levels challenges organisations and institutions. Boundary management seems to be a substantial part of everyday organisational life. Consultants who work in organisations cannot ignore this reality.

Lawrence (1999) makes the point that the trend in society to move away from categorising people has de-emphasised boundaries. In his view, one needs to recognise boundaries, but they must remain open to inquiry. The role of consultants is to work with managing boundaries and to make teams and leaders aware of boundary management issues (Cilliers \& Koortzen, 2005).

When consulting about boundaries, many boundaryrelated issues face psychologists. They include unclear boundaries, boundaries that are too small, too loose, too tight, shared, or well defined (Haslebo \& Nielsen, 2000). Clients may be concerned that they have compromised their boundaries, that they have been excluded from a boundary or that certain boundaries are conflicted. They might want to cross a boundary, push it, form one, change one, remove it, understand it, share it, question it or break it down. Organisational boundaries seem to be a logical focal point for consultants who wish to approach organisations from a complex and systemic paradigm, whilst systems psychodynamics provide an approach to boundary-related issues in organisations.

\section{Research purpose}

The purpose of the research was to produce a theoretical set of assumptions about organisational boundaries and boundary management and, from these assumptions, to develop a set of hypotheses as a thinking framework for practising consulting psychologists when they work with boundaries from a systems psychodynamic stance. The study focused on individual, group and organisational boundaries as consultants' points of engagement with organisations. More specifically, it focused on boundary management as a phenomenon in organisations and a focus of consultation.

The rationale was to work towards applying boundary management practically to the field of organisational consulting psychology as an applied science. According to Loveridge, Willman and Deery (2007), after 60 years of publication, the focus is still on multi-disciplinary approaches that connect social theory to social practice, which can contribute towards the well-being of employees and the effectiveness of organisations. Although the systems psychodynamic paradigm and theory is complex, it allows consultants entry into organisations' below the surface behaviour (Campbell \& Huffington, 2008; Huffington, Armstrong, Halton, Hoyle \& Pooley, 2004). Heracleous (2004) makes this point when he calls for grounded research on organisational boundaries that focus on the first-order perceptions of stakeholders in an organisational context.

According to the literature, the systems psychodynamic view of organisations looks beyond the rational and economic view of work (Sievers, 2009). It focuses on organisations as living systems that are both conscious and unconscious (Colman \& Bexton, 1975; Colman \& Geller, 1985; Cytrynbaum \& Noumair, 2004). Fraher (2004) traces the roots of the approach to classical psychoanalysis, group relations theory and open systems theory. The systemic aspects of this paradigm give obvious importance to the concept of boundaries, because these define what is inside or outside of systems or any parts of them (Campbell \& Huffington, 2008; Churchman, 1968; Diamond \& Allcorn, 2009). Boundaries help us to make sense of the world. They give us a way of classifying and categorising, without which the here-and-now would be chaotic and intolerable (Stapley, 1996; 2006). Boundaries, seen in this way, provide people with a sense of safety and control. Boundary management concerns working with what is inside versus what is outside through internal integration and external adaptation (Gould, 1993; Klein, 1959; 1997; Schein, 2004).

\section{Trends from the research literature}

The systems psychodynamic literature review provided the researcher with eight assumptions about organisational boundaries and boundary management. The first is that 'boundary management happens between people and in the minds of people. Therefore, boundary management is a social and psychological process'.

In the context of organisations, groups and people, boundaries are related and inter-related (Hernes, 2004; Lawrence, 1999; Stapley, 1996; 2006). The interplay and tension between people and groups, groups and organisations as well as between organisations and their environments are the contexts of boundary management. Boundaries are social constructs that exist in the minds of people. These conceptualisations may be individual or shared. The psychological and social view of boundaries means that boundary management concerns learning and negotiating. For effective functioning, the subsystems of organisations (including people) need to learn what their boundaries are and negotiate these with other parts of their organisations. The processes of learning and negotiating occur at the same time. Because boundaries are socially constructed, they can also be socially deconstructed, unlearned and re-negotiated. 
The second is that there are five key differentiating constructs that define boundaries in the minds of people and in organisations. These are identity, role, task, authority and capability'. Identity, role, task, authority, and capability are primarily psychological constructs (Koortzen \& Cilliers, 2002; Hayden \& Molenkamp, 2002; Hirschhorn \& Gilmore, 1992; Santos \& Eisenhardt, 2005). In other words, they exist in the minds of people (Diamond, Allcorn \& Stein, 2004; Hirschhorn \& Gilmore, 1992). The idea of 'organisation in the mind' (Armstrong, 2005) extrapolates to 'boundaries in the mind'. The constructs of capability, identity, authority, role and task are the building blocks of these boundaries. For example, authority in the mind may refer to the construction of people's own authority as they understand or perceive it. This construction is a psychological one about people's relationships with, and relatedness to, others. This construction in the mind carries inherent boundaries with it. One can argue that people, groups and organisations use the constructs of identity, authority, capability, role and task to answer the question 'who am I and not I, us and not us' (Hirschhorn \& Gilmore, 1992; Stapley, 2006).

The third is that 'each boundary construct contains conscious and unconscious aspects'. If the proposed boundary constructs are essentially psychological ones, then they will also have psychological properties, in this case both conscious and unconscious constructions in the mind of people (Stapley, 2006). One can define the boundary between leaders and followers in conscious terms by using the proposed constructs. Team leaders might have titles, job descriptions, role descriptions, formal responsibilities and distinct abilities that would clearly differentiate them from followers. On an unconscious level, the same relationship might also have, under the surface, a parent-child construction. The unconscious emotional needs of followers might define different roles and tasks for team leaders and vice versa (Lawrence, 1999).

The fourth is that 'there are two aspects to each boundary. These are in-lines and out-lines'. The in-line consists of the identity, role, task, authority and ability that A (people, groups or organisations) thinks it has, whereas the out-line consists of how B (other people, groups or organisations) perceives the identity, role, task, authority and ability of A (Miller, 1985a). This principle brings the social aspect of boundary management into play. If one sees it in this way, one may share or not share a boundary, recognise or not recognise it. This also suggests that a boundary may exist for one but not for the other. This aspect of the theory provides an understanding of boundary confusion and conflict.

The fifth is that 'people, groups or organisations can only control their in-lines. They need to negotiate their outlines'. If a boundary exists for particular people, teams or organisations, others will not automatically recognise, accept, authorise or support it (Miller, 1985b). Sometimes they need to explain, negotiate, agree to or even enforce a boundary before others authorise or recognise it.
The sixth is that, 'for people in the same team or organisation to share an in-line, negotiation is necessary between them'. A shared understanding of the boundary of a team requires a meeting of minds between the people in the team (Gundlach, Zivnuska \& Stoner, 2006; Roberts \& Dutton, 2009). A shared set of assumptions about identity, role, task, authority and ability is an in-line (or shared) concept of the team's own boundary.

The seventh is that 'physical and psychological boundaries are related and interrelated'. It is the belief that psychological boundaries result in physical boundaries or barriers and vice versa (Diamond, Allcorn \& Stein, 2004; Hirschhorn \& Gilmore, 1992). People, who identify with each other, will, more often than not, see themselves as a group in some way or another, for example in language, dress or proximity. These physical artefacts are the result of their psychological boundaries. On the other hand, if people create a physical boundary between or around others, they will respond to it psychologically more often than not. In the same manner, boundaries are spilling over into organisations and vice versa. They also reflect one-another (Campbell \& Huffington, 2008).

The eighth is that 'integration and differentiation are interrelated and complementary activities in organisations and lie at the centre of boundary management'. Lewis and Kelemen (2002, p. 251) observed that organisations face 'contradictory demands for control and autonomy, coordination and individuality, expansion and contraction'. Theories of integration and differentiation in organisations explain how they deal with these paradoxical demands. Integration refers to the process by which the members of groups or organisations create shared psychological beliefs that relate and connect. Differentiation is the social and psychological process by which people, groups and organisations draw distinctions between themselves and others. Organisations that have high levels of integration and differentiation at the same time perform better than those who do not (Lawrence, 1999). Managing these two antagonistic states seems to be an essential task for the performance and survival of organisations.

These are theoretical assumptions about organisational boundaries and boundary management. The boundaries are multi-dimensional and dynamic. They are multi-dimensional because they are physical and psychological, individual and collective (shared), conscious and unconscious. They are dynamic because they are related and interrelated.

This applies to each of the boundary dimensions mentioned earlier. For example, people's personal moral boundaries relate to, and interrelate, with the moral boundaries of society. The conscious aspects of those moral boundaries will also relate to, and interrelate with, unconscious beliefs and assumptions. These psychological conceptualisations will lead, in turn, to physical or artefactual behaviour (Schein, 2004). These boundaries also consist of central concepts or differentiators. 
In this study, the researcher sees identity, role, task, authority and capability as the primary differentiators of boundaries and as boundaries in their own right - they are multidimensional. This means that each of the differentiators has conscious, unconscious, physical, psychological, individual and collective attributes. This understanding of boundaries and boundary management led to the research questions that follow:

- what is the primary task of boundary management

- what does the systems psychodynamics of boundary management in organisations mean?

\section{The potential value-add of the study}

The value of this study lies in its offer of a set of qualitatively verified assumptions about organisational boundaries and boundary management as a way of making sense of anxiety and chaos in organisations. The study addressed the typical scenario of a range of experiences that confront consultants. They need to distinguish, compare and connect them to make sense (Oliver, 2005). Here consultants ask questions like:

- what part of the organisations should they work with

- where do consulting assignments start and where do they end

- who are the clients

- what do the scopes include and what do they exclude

- what is really going on

- what should they work with and what should they not work with? (See Dillon, 2003).

This sifting process helps consultants to change holistic and systemic insights about organisations into practical consulting work. Without this process, consultations will never move from the conceptual to the practical. It is here that this research focuses on the interface between relationships in organisations, that is, on their boundaries. This gives consultants a useful and practical platform that might assist them to balance the complex conceptual world with the practical consulting one.

\section{What will follow}

The structure of rest of the article follows. The researcher presents the research design, the research approach and research strategy. The research method follows. It consists of the setting, the roles of the researchers, the sampling method, data collection, recording and analysis. The researcher then mentions the strategies he used to ensure quality data. He then presents the findings for cases A and $\mathrm{B}$, the themes that emerged and the working hypotheses. The discussion contains the answers to the two research questions. The conclusion follows and the article concludes with recommendations, possible limitations of the study and suggestions for further research.

\section{Research design \\ Research approach}

The approach was qualitative (Terre Blanche, Durrheim \& Painter, 2006) and interpretive (Gorton, 2006; Yanow
\& Schwartz-Shea, 2006). Hermeneutics was the research paradigm (Scott \& Keetes, 2001). The researcher chose this paradigm because of his belief that reality and truth are internal and subjective. Using these approaches, the study tried to answer the 'how' and 'why' questions of boundary management in a thick, rich and varied description (Alvesson \& Sköldberg, 2010).

\section{Research strategy}

The researcher used a two case study design (Woodside \& Wilson, 2003). This is the description of an ongoing event ... in relation to a particular outcome of interest ... over a fixed time in the here and now' (Brewerton \& Millward, 2001, p. 53). The case studies were instrumental (Denzin \& Lincoln, 2000) to gaining an understanding of boundary management and to elaborate on and extend the relevant theory.

\section{Research method}

\section{Research setting}

The researcher conducted the research in the South African head office of an international specialist banking group with global divisions. It served a niche client base. Its organisational model balanced centralisation with decentralisation to facilitate control and provide focus to its business units. The two case studies are from different autonomous specialist business units. The organisation is structured for nimbleness, flexibility, a high level of decision-making authority - that is rarely overridden - and decentralised support functions.

\section{Entrée and establishing researcher roles}

The first researcher played three distinct roles. The first was as consultant (Lowman, 2002) to the organisation. The second was as participant observer (Brewerton \& Millward, 2001) who witnessed, described, recorded and made sense of the consultation whilst being part of it at the same time (Dewalt \& Dewalt, 2002). The third was as discourse researcher (Cilliers \& Smit, 2006) who analysed the research data. He used the orientation of self as the instrument of analysis (Clarke \& Hoggitt, 2009; McCormick \& White, 2000). The second researcher was the supervisor (see Clarke \& Hoggett, 2009).

\section{Sampling}

The researcher used convenience and purposive sampling to 'examine particular instances of the phenomenon of interest' (Teddle \& Tashakori, 2009, p. 177) in order to define and elaborate on the manifestation of boundary management. The researcher chose the two cases to yield different organisational-level data. Case A happened on a micro level. It focused on the intergroup dynamics (Brunner, Nutkevitch \& Sher, 2006) of specific teams in a single division and with the same geography. Case B occurred on a macro group-as-whole scale (Brunner et al., 2006; Wells, 1985). It included divisions of the whole organisation with different geographies. It had several support functions throughout the organisation. As Teddle and Tashakori (2009) suggested, 
Case B supplemented Case A in its scale and holistic nature. All role players were present and the conversation involved the whole organisation.

\section{Data collection methods}

The researcher used the diary method (Brewerton \& Millward, 2003) during the consulting sessions. He made detailed written field notes (of thoughts, feelings, realisations and insights) during and after each consulting session. He conducted ethnographic interviews (Flick, 2009) for case A, with its head and his team leaders. He used focus groups (Bernard, 2006) for Case B with each team after ending the consultation. The question he asked for both techniques was 'what is your experience of your division?'

\section{Recording of data}

The researcher used the diary material in its original form. During the interviews and the focus groups, he recorded the verbatim material in detail and immediately afterwards transcribed it to ensure that he had captured all the detail. He kept and stored the data safely.

\section{Data analyses}

The researcher used discourse analysis (Camic, Rhodes \& Yardley, 2003; Denzin \& Lincoln, 1994), which he interpreted from the systems psychodynamic stance (see Cilliers \& Smit , 2006; Armstrong, 2005; Campbell, 2007; Cilliers \& Koortzen, 2005; Gould et al., 2001; Huffington, et al., 2004; Klein, 1997). The researcher categorised the case study data into themes that relate to boundary management. He formulated working hypotheses for each of the two cases and viewed them in relation to one other (Terre Blanche et al., 2006). He then finalised the hypotheses for each case study by merging the hypotheses that built on each other or by separating the hypotheses that needed more focus. This yielded a set of hypotheses for each of the two cases. The next step was to accumulate findings from both cases. He checked the coherence of the hypotheses (Terre Blanche, 2006) that emerged from the two cases and followed the process of merging and separating once more. A final set of hypotheses emerged. The researcher checked it against the data from the two case studies and finally correlated it with the existing literature.

\section{Strategies employed to ensure quality data}

The researcher ensured validity and reliability by following the suggestions of Denzin and Lincoln (1994), Riege (2003) and Terre Blanche et al., (2006). Construct validity refers to using several sources of evidence, establishing a chain of events and reviewing a draft case study report. The internal validity of findings refers to crosschecking data during analysis.

Reliability refers to giving a full account of the theories and ideas for each research phase, assuring congruence between research issues and the features of the study, recording actions and observations in writing as well as using peer reviews.
Ethicality refers to informed consent and confidentiality in terms of contracts with managers and team members. The researcher tried to show respect for the participants and their shared personal information in the cases and in the analysis of the data (Holloway \& Jefferson, 2010).

\section{Reporting}

The researcher presented the findings by case study, followed by the five manifested themes. He gave answers to the research questions in the discussion.

\section{Findings}

The researcher reported the findings for cases A and B by referring to the consulting context and his experience.

\section{Case A: Leadership in Business Support Services}

The client was the operations unit of the investment banking division. The primary task of this business unit was to generate income by growing and preserving the assets of clients. Its structure was a front and a back office that operated in different office areas to facilitate its undivided attention on its primary tasks.

The primary task of the front office was to offer clients relevant advice and portfolio management services by focusing on protecting capital and growth in local and international investments. The primary task of the back office was to support the front office through information technology (IT), administrative support and solutions.

The focus of this case study was the functions of the back office, called Business Support Services (BSS). It provided full support to the securities division, and services to third parties, in an attempt to generate its own income. As this strategy interfered with the level of service to internal clients, management decided to split it into two separate entities, one with a focus on internal clients only.

'Settlements' became an area on its own whilst the operational support area became a separate entity called BSS. BSS comprised several teams that were mostly IT related. They included:

- business analysis

- service desk and statements

- development infrastructure

- an incentive scheme.

Each of these teams had its own team leader who, in turn, reported to the head of BSS. He, in turn, reported to the head of the securities division through the chief operating officer (COO) of Securities, who was responsible for all back office areas.

\section{Case A consultation}

The consultation sessions focused on the inability of different teams and areas within BSS to relate and collaborate. There were several splits in the area. They led to fragmentation and 
ultimately inhibited the unit from performing its primary task. The consultant's analysis of the collaboration issues suggested poorly negotiated boundaries in the area. More specifically, the consultant believed that the identity, role and primary task of the back office were not clearly defined and negotiated with the front office. This led to conflict and discrepancies in expectations and delivery. This also resulted in the de-authorisation of the back office.

For example, developers in the IT department were seen as service providers rather than as strategic partners. Therefore, they were often excluded from business strategy meetings. This led to unrealistic development requests that the IT department could not meet. This, in turn, frustrated the front office that needed speedy IT delivery in order to improve its work. The consultant gave the leaders of the back office an opportunity to understand clearly their own identities, roles and primary tasks. Once these became shared concepts in their own minds, they were able to negotiate boundaries with their colleagues in the front office.

This work enabled leaders of the back office to redefine their leadership roles. They made a significant shift from being essentially managers to leaders of their division. This shift led to a watershed strategy session for the division. The leadership team presented the BSS strategy as a journey, starting with the state of affairs 20 months into the history of the function and ending with plans for the new quarter. Not only did the team leaders show their intention to lead the division during this process but they also started to contain anxiety in the system. They communicated their philosophy about people and their intention to create a much more caring environment: 'We do regard the people as our most important asset'. They also communicated the relationship that they intended to create with the front office, which was 'to be strategic partners with our clients'. This change helped the leaders to get closer to their staff. The head of the area was stunned by the impact of the session. The staff for the first time seemed to be more aligned. He described it as a sense of solidarity.

The consultant ultimately approached the entire consultation as boundary work. The back office renegotiated the boundary between itself and the front office along the parameters of identity, role and task. The leaders in the back office also created a shared concept of their own boundary with each other (in-line). The leaders also re-negotiated the boundary between themselves and their staff. During this process of alignment and re-negotiation, the consultant worked with both conscious and unconscious material relating to boundaries. The consultant assisted the team leaders to redefine their role from 'task masters' who drove tasks to that of 'leaders' who gave direction, built relationships and provided a context for performance to their staff. The leaders communicated this shift in intention clearly to their staff. They also assisted the staff to bring to the surface their own inabilities, which they had previously denied.

The consultant then helped the leaders in the back office to align their capabilities with their newly negotiated boundaries. The interplay between identity, role, task, authority and capability formed the central theme of the consulting work. The consultant treated these constructs as the building blocks of the boundaries. Here, the team leaders made an identity shift from 'service providers' to 'strategic partners' and from 'managers of tasks' to 'leaders of people'. These identity shifts led to consultation on how they played their roles in the organisation. This, in turn, led to new tasks they needed to perform, which raised new competency challenges. Negotiating authority for this shift in roles and tasks then came into play.

\section{Case B: Information security in an international specialist banking group}

The client was the international specialist banking group. The particular consulting process occurred on an organisational level. It pivoted on the theme of information security. Information was a key asset of the organisation. Therefore, it needed to manage its information appropriately and protect it from a wide range of risks to ensure competitive advantage and business continuity. Implementing an appropriate set of controls, which comprised policies, standards, procedures, structures and technology configurations, would improve information security.

This organisation allocated the task and responsibility for managing and protecting information to the group information security officer (GISO). The GISO operated with a small team of people, the Information Security Team (known as the Info Sec Team). The primary task of the Info Sec Team was to manage and protect the organisation's information. The GISO and his team were ultimately responsible for producing policies, standards and procedures related to information security. The business units had to implement them. Some of the GISO team members acted as consultants to the business units, assisting them to implement these policies and helping them to identify specific threats to the business units.

The structure of IT in this organisation is largely decentralised. Each business unit has an IT division. A separate division, known as Central IT (CIT), was responsible for the IT infrastructure (including hardware, servers and voice technology) whilst a small team of people shouldered the responsibility of Group IT. Group IT takes strategic leadership. It is accountable for the whole IT domain in the organisation, including information security. Other role players and forums of significance to this case study included:

- Group Risk

- Internal Audit

- the Technical Architecture Board (TAB).

Group Risk performed the primary task of reducing the organisation's exposure to risk. The Internal Audit function helped the organisation to achieve its stated goals by analysing business processes, activities and procedures, highlighting problems and providing solutions. TAB was an advisory and decision-making forum that focused on all technical and architectural aspects of IT. It comprised key 
members of the Group IT Management Committee (Manco) and other technical experts.

\section{Case B consultation}

The consultation process focused on the de-authorisation of the Info Sec Team. The identity, role and task of this team had not been clearly communicated to, and negotiated with, the organisation. The Info Sec Team described its primary task (Rice, 1963) as 'to protect the organisation's information'. However, the IT divisions in the business units saw this task as their responsibility. They were not interested in the proposals of the Info Sec consultants, nor did they support the role of the GISO. This led to misalignment and conflict with the business units that they were supporting. The business units said that Group IT and the GISO were 'telling them what to do'. The initial consulting sessions focused on re-negotiating the identity, role and primary task of the Info Sec Team with the rest of the organisation. However, as the consultation progressed, the focus shifted towards information security as an activity.

A three-day institutional event (Brunner, Nutkevitch \& Sher, 2006) followed. The role players agreed and negotiated their roles and responsibilities in relation to information security in the group. Two very distinct primary tasks emerged for the Info Sec team and the business units. The primary task for the Info Sec team was 'oversight and promotion of information security within the group'. They were not authorised to execute tasks on behalf of the business units and they were not responsible for implementation or 'product selection'. The business units, on the other hand, now had to 'ensure that the group's environment is secure'. This was a fundamental shift in their primary task.

\section{Integration}

The researcher used the constructs of identity, role, task, authority and capability as the parameters that defined the boundary negotiations throughout. Five themes emerged from the data.

Theme 1: Interaction between authority, capability, identity, role and task: Both cases showed that the constructs of authority, capability, identity, role and task were related and interrelated.

Theme 2: Differentiation and boundaries: There was substantial evidence in each of the cases that the organisation's subsystems differentiate themselves from others based on authority, capability, identity, role and task.

Theme 3: Integration and boundaries: The data suggested that the subsystems of the organisation, like teams and divisions, integrate through sharing a collective conceptualisation of their own authority, capability, identity, role and task.

Theme 4: Misalignment and fragmentation: Both cases showed that misalignment between the different subsystems of the organisation, in terms of authority, capability, identity, role and task, might lead to its fragmentation.
Theme 5: The adverse effects of boundary problems: The data suggested that boundary problems may lead to conflict and stress that might adversely affect the functioning of the organisation. Using these themes, the researcher formulated the six working hypotheses that follow:

- Working hypothesis 1: There is a natural balance between capability, authority, identity, role and task. When the balance is disturbed, the system will re-organise to restore the equilibrium.

- Working hypothesis 2: When one part of a system differentiates itself from another in terms of capabilities, authority, identity, role and task, a psychological boundary forms between them.

- Working hypothesis 3: When one part of a system shares capabilities, authority, identity, role or tasks with another, they share a psychological boundary.

- Working hypothesis 4: Misalignment between different parts of organisations, in terms of capability, authority, identity, role and task, can lead to their fragmentation.

- Working hypothesis 5: Alignment between different parts of organisations, in terms of capability, authority, identity, role and task, can lead to integration.

- Working hypothesis 6: Boundary management can reduce conflict and stress as well as their dysfunctional effects.

\section{Discussion}

The first purpose of the research was to produce a theoretical set of assumptions about organisational boundaries and boundary management. Using these assumptions, its second purpose was to develop a set of hypotheses as a thinking framework for practising consulting psychologists when they work with boundaries from a systems psychodynamic stance. The findings could provide a useful and practical consulting platform that might help consultants to balance the complex conceptual world with the practical consulting one when it comes to boundary management consulting.

The researcher answered the first research question ('what is the primary task of boundary management?'). It is 'to hold the polarities of integration and differentiation and not allow the system to become fragmented or overly integrated'. The researcher answered the second research question ('what does the systems psychodynamics of boundary management in organisations mean?'). It 'is an activity in organisations that happens continuously at all levels and involves whole organisations' (also see Fuqua \& Newman, 2002).

The tendency of organisations to move through repeating cycles of centralisation and de-centralisation is proof that there is no ideal point of balance between integration and differentiation (Lawrence \& Lorsh, 1967; Schneider, 1985; Schein, 2004). In practice, this refers to the continuous processes of aligning and negotiating that happens between people and groups (Hirschhorn \& Gilmore, 1992). The ultimate task of boundary management is to create a balance between being flexible, adaptable (necessary for the survival of postmodern organisations) - see Lewis \& Kelemen (2002) 
- and connected. Without relationships and collaboration, there is no organisation (Gundlach et al., 2006; Hernes; 2004).

Subsystems of organisations, like teams and divisions, differentiate and integrate according to their distinct identities, roles and tasks. They also do this through the ways that they are authorised and the capabilities that they have (Koortzen \& Cilliers, 2002; Hayden \& Molenkamp, 2002; Hirschhorn \& Gilmore, 1992; Santos \& Eisenhardt, 2005). Organisations make sense of the complex range of tasks and activities they need to perform by differentiating, thereby giving them focus. Clear differentiation helps people to know what their responsibilities are and what they need to do. They also contain unconsciously on behalf of their organisations (Hyde, 2006). Without differentiation, being aware of boundaries as well as the classification and categorisation that they provide, organisations would be unmanageable - and working in them would be untenable (Stapley, 1996; 2006).

Different teams and divisions focus on different strategic areas. Each develops its own special skills and knowledge (Dosi, Faillo \& Marengo, 2009). They continuously discover who they are, what they should be doing and who should be in charge in relation to others in their organisations (Hirschhorn \& Gilmore 1992; Schein, 2004). In case A, this form of functional differentiation was very apparent between the front office staff and their back office support. However, too much differentiation can lead to disconnected organisations. This could happen when teams and divisions become so differentiated that they break off, or become completely disassociated, from the rest of their organisations (Gundlach et al., 2006). This is precisely what happened in Case A. Important role players were excluded from business strategy discussions. It led to strategic decisions that were difficult to implement.

Shared capabilities, authority, identity, roles and tasks integrate teams and subsystems in organisations (Gundlach et al., 2006). It brings people together, focuses their collective efforts and creates a sense of belonging. In case A, the leaders of BSS used a two-day dialogue session to create a shared sense of identity, role and task. This helped them to create a leadership team coming from 'a group of individual leaders who each do their own thing'. When organisations become too integrated, they become rigid, overly controlled and inflexible (Lawrence \& Lorsch, 1967).

The interrelated nature of the constructs of capability, authority, identity, role and task was apparent in these research findings. This showed face validity. Tasks and roles are intricately entangled in organisations. Every role has a task and all tasks seem to belong to a role. People in organisations identify themselves according to their roles and tasks because they relate to their primary tasks and, therefore, to the very essence of their organisations. Furthermore, in order to perform tasks or play roles, there needs to be a set of related abilities.
Finally, all people and teams in organisations exist in relation to each other. Roles and tasks are not possible if they are not authorised. The interrelatedness of these constructs gives consultants several points from which to work when boundaries are involved. In theory, boundary management can start with any of the constructs. Working with one will activate the others and bring them into the consulting process.

In Case B, the consultant worked with several different subsystems of the organisation to re-negotiate their responsibilities in relation to information security. These re-negotiations of responsibilities related closely to the authority, role, identity and capability boundaries of each area. Conflict arises when the subsystems of organisations do not agree on their boundaries. Conflict leads to splits and splits lead to breakdowns in communication, relationships, collaboration and ultimately in the organisations' ability to perform their primary tasks (Hyde, 2006). Both case studies showed this clearly.

In Case A, boundary disagreements between the front and back office created much animosity. In Case B, boundary confusion left the team de-authorised and incapable of performing its tasks. In this research, the constructs of capability, authority, identity, role and task were boundaries in their own right. It seems that people and teams constantly need to manage their boundaries in their organisations through negotiating these constructs with each other. Without this, misalignment and breakdown will happen. This reinforces the need for alignment (Haslebo \& Nielsen, 2000). In order for the differentiated parts of organisations to connect with each other, there must be alignment (Gundlach et al., 2006). This alignment across boundaries happens when two or more parts of organisations have similar 'organisations in the mind'. When different parts of organisations have aligned ideas of the identities, roles and tasks of others, and when these subsystems have corresponding abilities, they are able to authorise each other, communicate, build relationships, collaborate and ultimately perform their primary tasks. All of this helps to integrate organisations.

In both cases, the consultant helped the different subsystems of the organisation to understand and agree on their boundaries in relation to, and with, others. These interventions helped the organisation to integrate and made greater collaboration and performance possible.

\section{Conclusions}

The researcher concluded that effective boundary management leads to good holding environments that, in turn, lead to containing difficult emotions in organisations. Staff members negotiate organisational boundaries. They exist in the minds of the staff rather than in the formal structures of organisations' hierarchies. Identity, role, task, capability and authority are prominent concepts in the individual and collective minds of people. They comprise the boundaries in organisations. The principles of boundary management consulting the researcher reached in this research will assist 
consultants to work with organisational boundaries in a multi-dimensional way. Consultants who operate from this perspective can engage with organisational boundaries as physical, psychological, individual, collective, conscious and unconscious phenomena. The multi-dimensional focus of the principles makes them flexible. It also accounts for complexity but makes the work manageable at the same time.

\section{Recommendations}

The researcher recommends that organisations work at managing their boundaries effectively. This suggests that organisations need to create environments where people are relatively free to negotiate their own boundaries with each other and where hierarchy and power do not interfere with this process. Organisations must try very hard to create spaces and practices for communication that will improve effective boundary management.

The researcher also recommends that teams and departments invest the necessary time to talk about their own identities, roles, tasks, authority and abilities. These discussions will facilitate shared understanding about these internal boundaries, which would enable them to negotiate those same boundaries more effectively with other areas of the organisations in which they work. Organisations should become aware of the balance between integration and differentiation if they want to succeed. Organisations that are overly controlled and bureaucratic should differentiate themselves more, whilst organisations that seem to be fragmented and misaligned should integrate themselves more fully.

\section{Possible limitations of the study}

The researcher identified the limitations that follow. Firstly, the researcher chose five constructs as primary boundary differentiators based on the literature, as well as his knowledge, experience and intuition. Although he found enough empirical evidence to support the relevance of these constructs, future research could investigate the existence of other constructs. For example, Hirschhorn and Gilmore (1992) included political boundaries.

Secondly, using working hypotheses as a tool of analysis has inherent limitations because they do not present absolute truths - they are only applicable and usable until someone proves that they are not. Amado (1995) believes that working hypotheses as research tools always require researchers to check the assumptions.

Thirdly, the consultant and researcher was the same person. This was a limitation because the qualitative research instrument had very human limitations. Therefore, it is difficult, if not impossible, to comment on how the levels of knowledge, insight and experiences of the consultantresearcher, as well as his unconscious processes, influenced the consultation and research processes.

\section{Suggestions for further research}

In terms of future research, the researcher suggests that researchers explore the working hypotheses presented in this research in other organisations or in different consulting contexts.

Researchers could also test the consulting framework with different consultants. Researchers could apply different research designs to test these findings and hypotheses. For example, they could use them in a group relations training event. This would provide a semi-controlled environment for testing and analyses. Researchers could also use a longitudinal study to test the effect of the consulting intervention. Lastly, researchers could add more elements to authority, ability, identity, role and task as boundary constructs. For example, researchers could explore the political elements of boundaries more fully as the present study almost totally omitted them.

\section{Acknowledgements Competing interests}

The authors declare that they had no financial or personal relationship(s) which may have inappropriately influenced them when they wrote this paper.

\section{Authors' contributions}

Both researchers planned the research project. H.S. (University of South Africa) conducted the literature review and the empirical study. F.C. (University of South Africa) acted in a supervisory role and took responsibility for publishing the material and the academic editing.

\section{References}

Alvesson, M., \& Sköldberg, K. (2010). Reflexive methodology. New vistas for qualitative research. London: Sage.

Amado, G. (1995). Why psychoanalytical knowledge helps us understand organisations: a discussion with Elliot Jaques. Human Relations, 48(4), 351-357. http://dx.doi.org/10.1177/001872679504800402

Armstrong, P. (2005). Organisation in the mind. London: Karnac.

Bernard, H.K. (2006). Research methods in anthropology. Oxford: Alta Mira Press.

Brewerton, P., \& Millward, L. (2001) Organizational research methods: A Guide for students and researchers. London: Sage Publications Ltd.

Brunner, L.D., Nutkevitch, A., \& Sher, M. (2006). Group relations conferences. Reviewing and exploring theory, design, role-taking and application. London: Karnac.

Camic, P.M., Rhodes, J.E., \& Yardley, L. (2003). Qualitative research in Psychology. Washington: APA.

Campbell, D. (2007). The socially constructed organisation. London: Karnac.

Campbell, D., \& Huffington, C. (2008). Organisations connected. A handbook of systemic consultation. London: Karnac.

Churchman, C.W. (1968). The systems approach. New York: Doubleday Dell Publishing Group.

Cilliers, F., \& Koortzen, P. (2005). Conflict in groups: The CIBART model. HR Future, $113(10), 52-53$.

Cilliers, F., \& Smit, B. (2006). A systems psychodynamic interpretation of South African diversity dynamics: a comparative study. South African Journal of Labour Relations, 30(2), 5-18.

Clarke, S., \& Hoggett, P. (2009). Researching beneath the surface. Psycho-social research methods in practice. London: Karnac.

Colman, A.D., \& Bexton, W.H. (1975). Group relations reader 1. Jupiter: The A.K. Rice Institute.

Colman, A.D., \& Geller, M.H. (1985). Group relations reader 2. Jupiter: The A.K. Rice Institute. 
Cytrynbaum, S., \& Noumair, A. (2004). Group dynamics, organizational irrationality, and social complexity: Group relations reader 3. Jupiter: A.K. Rice.

Czander, W.M. (1993). The psychodynamics of work and organizations. New York: Guilford.

Denzin, N.K., \& Lincoln, Y.S. (1994). Handbook of qualitative research. Thousand Oaks: Sage.

Dewalt, K.M., \& Dewalt, B.K. (2002). Participant observation: a guide for fieldworkers. Oxford: Alta Mira Press.

Diamond, M.A., \& Allcorn, S. (2009). Private selves in private organizations. The psychodynamics of organisational diagnosis and change. New York: Palgrave Macmillan.

Diamond, M.A., Allcorn, S., \& Stein, H. (2004). The surface of organizational boundaries: a view from psychoanalytical object relations theory. Human Relations, 57(1), 31-49. http://dx.doi.org/10.1177/0018726704042713

Dillon, J.T. (2003). The use of questions in organizational consulting. The Journal of Applied Behavioral Science, 39(4), 438-452.

Dosi, G., Faillo, M., \& Mrengo, L. (2008). Organizational capabilities, patterns of knowledge accumulation and governance structures in business firms: an introduction. Organization Studies, 19(8\&9), 1165-1185. http://dx.doi. org/10.1177/0170840608094775

Flick, U. (2009). An introduction to qualitative research. (4th edn.). London: Sage.

Fraher, A. (2004). A history of group study and psychodynamic organisations. London: Free Association.

Fuqua, D.R., \& Newman, J.L. (2002). The role of systems theory in consulting psychology. In Lowman, R.L. (Ed.), Handbook of organizational consulting psychology. San Francisco: Jossey-Bass.

Gould, L.J. (1993). Contemporary perspectives on personal and organisational authority: the self in a system of work relationships. In L. Hirschhorn \& C.K Barnett (Eds.), The psychodynamics of organisations Philadelphia: Temple University Press.

Gould, L.J., Stapley, L.F., \& Stein, M. (2001). The systems psychodynamics of organisations. London: Karnac.

Goldkuhl, G. (2002). Anchoring scientific abstractions: ontological and linguistic determination following socio-instrumental pragmatism. European Conference on Research Methods in Business Management (ECRM 2002), Reading, 29-30 April 2002.

Gorton, W.A. (2006). Karl Popper and the social sciences. New York: State University of New York Press.

Gundlach, M., Zivnuska, S., \& Stoner, J. (2006). Understanding the relationship between individualism-collectivism and team performance through an integration
of social identity theory and social relations model. Human Relations, 59(12), of social identity theory and social relations model. Hum
1603-1632. http://dx.doi.org/10.1177/0018726706073193

Haslebo, G., \& Nielsen, K.S. (2000). Systems and meaning: consulting in organisations. London: Karnac.

Hayden, C., \& Molenkamp, R. (2002). Tavistock Primer, London: Tavistock.

Heracleous, L. (2004). Boundaries in the study of organization. Human Relations, 57(1), 95-103. http://dx.doi.org/10.1177/0018726704042716

Hernes, T. (2004). Studying composite boundaries: a framework of analysis. Human Relations, 57(1), 9-29. http://dx.doi.org/10.1177/0018726704042712

Hirschhorn, L., \& Gilmore, T. (1992). The new boundaries of the "boundaryless" company. Harvard Business Review, 70(3), 104-115.

Holloway, W., \& Jefferson, T. (2000). Doing qualitative research differently. Free association, narrative and the interview method. London: Sage.

Huffington, C., Armstrong, A., Halton, W., Hoyle, L., \& Pooley, J. (2004). Working below the surface. The emotional life of contemporary organisations. London: Karnac.

Hyde, P. (2006). Managing across boundaries: identity differentiation and interaction. Journal of Innovation and Learning, 3(4), 349-362.

Kegan, R. (1994). In over our heads: the mental demands of modern life. Cambridge, MA: Harvard University Press.

Klein, M. (1959). Our adult world and its roots in infancy. Human Relations, 12, 291303. http://dx.doi.org/10.1177/001872675901200401

Klein, M. (1997). Envy and gratitude and other works 1946-1963. London: Hogarth
Koortzen, P., \& Cilliers, F. (2002). The psychoanalytical approach to team development. In R.L. Lowman (Ed.), Handbook of organizational consulting psychology San Francisco: Jossey-Bass.

Lawrence, P., \& Lorsch, J. (1967). Differentiation and integration in complex organizations. Administrative Science Quarterly, 12, 1-30. http://dx.doi. org $/ 10.2307 / 2391211$

Lawrence, W.G. (1999). Exploring individual and organisational boundaries. A Tavistock open systems approach. London: Karnac.

Loveridge, R., Willman, P., \& Deery, S. (2007). 60 years of Human Relations. Human Relations, 60(12), 1873-1888. http://dx.doi.org/10.1177/0018726707084917

Lewis, M.W., \& Kelemen, M.L. (2002). Multiparadigm inquiry: Exploring organizational purism and paradox. Human Relations, 55(2), 251-275. http://dx.doi. org/10.1177/0018726702055002185

Lowman, R.L. (2002). The handbook of organizational consulting Psychology. San Francisco: Jossey-Bass.

McCormick, D.W., \& White, J. 2000. Using one's self as instrument for organisational diagnosis. Organisational Development Journal, 18(3), 49-62.

Miller, E.J. (1985a). Organisation development and industrial democracy. In A.D. Colman \& M.H. Geller (Eds.), Group relations reader 2 (pp. 243-271). Jupiter: A.K. Rice Institute.

Miller, E.J. (1985b). The politics of involvement. In A.D. Colman \& M.H. Geller (Eds.), Group relations reader 2 (pp. 383-397). Jupiter: A.K. Rice Institute.

Oliver, C. (2005). Reflexive inquiry: A framework for consultancy practice. London: Karnac.

Rice, A.K. (1963). The enterprise and its environment. London: Tavistock.

Riege, A.M. (2003). Validity and reliability tests in case study research: A literature review with "hands-on" applications for each research phase. Qualitative Market Research: An International Journal, 6(2) 75-86. http://dx.doi. org/10.1108/13522750310470055

Roberts, L.M., \& Dutton, J.E. (2009). Exploring positive identities and organizations Building a theoretical and research foundation. New York: Routledge.

Santos, F.M., \& Eisenhardt, K.M. (2005). Organizational boundaries and theories of organization. Organization Science, 16(5), 491-508. http://dx.doi.org/10.1287/ orsc. 1050.0152

Schein, E.H. (2004). Organizational culture and leadership. San Francisco: Jossey-Bass.

Schneider, S.C. (1985). Managing boundaries in organisations. In A.D. Colman \& M.H. Geller (Eds.), Group relations reader 2 (pp. 231-241). Jupiter: The A.K. Rice Institute.

Scott, J.W., \& Keetes, D. (2001). Schools of thought. Woodstock: Princeton University Press.

Sievers, B. (2009). Psychoanalytic studies of organizations. Contributions from the International Society for the Psychoanalytical Study of Organizations (ISPSO). London: Karnac.

Stapley, L.F. (1996). The personality of the organisation: A psycho-dynamic explanation of culture and change. London: Free Association.

Stapley, L.F. (2006). Individuals, groups and organisations beneath the surface. London: Karnac.

Teddle, C., \& Tashakkori, A. (2009). Foundations of mixed method research: Integrating quantitative and qualitative approaches in the social and behavioural sciences. San Francisco: Sage.

Terre Blanche, M., Durrheim, K., \& Painter, D. (2006). Research in practice. Applied methods for the social sciences. Cape Town: UCT Press.

Vansina, L.S., \& Vansina-Cobbaert, M. (2008). Systems psychodynamics for consultants and managers. Chichester: John Wiley \& Sons.

Wells, L. (1985). The group-as-a-whole perspective and its theoretical roots. In A.D. Colman \& M.H. Geller (Eds.), Group relations reader 2. Washington, DC: A.K. Rice Institute.

Woodside, A.G., \& Wilson, E.J. (2003). Case study research methods for theory building. Journal of Business \& Industrial Marketing, 18(6/7), 493-508. http:// dx.doi.org/10.1108/08858620310492374

Yanow, D., \& Swartz-Shea, P. (2006). Interpretation and method: Empirical research methods and the interpretive turn. NY: M.E. Sharpe. 